\title{
Modelling the distribution and relative abundance of feral camels in the Northern Territory using count data
}

\author{
S. R. McLeod ${ }^{\mathrm{A}, \mathrm{C}}$ and A. R. Pople ${ }^{\mathrm{B}}$ \\ A Vertebrate Pest Research Unit, Industry \& Investment New South Wales - Primary Industries, \\ Orange Agricultural Institute, Forest Road, Orange, NSW 2800, Australia. \\ ${ }^{B}$ Biosecurity Queensland, Primary Industries and Fisheries, Department of Employment, Economic Development \\ and Innovation, Alan Fletcher Research Station, PO Box 36, Sherwood, Qld 4075, Australia. \\ ${ }^{\mathrm{C}}$ Corresponding author. Email: steven.mcleod@industry.nsw.gov.au
}

\begin{abstract}
The objectives of this study were to predict the potential distribution, relative abundance and probability of habitat use by feral camels in southern Northern Territory. Aerial survey data were used to model habitat association. The characteristics of 'used' (where camels were observed) $v$. 'unused' (pseudo-absence) sites were compared. Habitat association and abundance were modelled using generalised additive model (GAM) methods. The models predicted habitat suitability and the relative abundance of camels in southern Northern Territory. The habitat suitability maps derived in the present study indicate that camels have suitable habitat in most areas of southern Northern Territory. The index of abundance model identified areas of relatively high camel abundance. Identifying preferred habitats and areas of high abundance can help focus control efforts.
\end{abstract}

Additional keywords: generalised additive model, habitat suitability, presence-only, pseudo-absence, resource selection function, habitat suitability, zero-inflated.

\section{Introduction}

Since their introduction to Australia in the late 1800 s and subsequent release into the wild, camels (Camelus dromedarius) have increased and spread across arid Australia (Edwards et al. 2004). Their broad-scale relationship with habitat has not been examined, but a species distribution model (Guisan and Thuiller 2005) could have several uses in camel management. Importantly, identifying preferred habitats can help focus control efforts. Furthermore, as camel numbers continue to increase, further expansion in the camel range is likely and knowledge of habitat preference will indicate likely habitats at risk of invasion (Edwards et al. 2008).

Current broad-scale distribution is known only as snapshots in time from infrequent aerial surveys. These surveys provide useful regional estimates of abundance, but at fine scales (e.g. $<10000 \mathrm{~km}^{2}$ ), density estimates are imprecise, leading to potentially misleading distribution patterns that may result in misdirected management effort. As an example, two identical surveys a short time period (e.g. 1 year) apart can yield quite different patterns of distribution, as only small numbers of camels are seen when both density and survey intensity are low. To overcome this problem, a spatial model linking habitat to the probability of occupancy can be used to predict camel distribution across the survey area.
Developments in statistical methods and the ease with which they can be linked to geographic information systems (GIS) has led to an increase in the number of studies using models to predict habitat distribution in recent years (Larson et al. 2008). Using a GIS, the attributes (biotic and abiotic characteristics) of sample sites can be easily recorded and used in resource selection function (RSF) models. Using this approach, predicted habitat distributions can be mapped and compared with other variables of interest such as areas of cultural or conservation importance.

A resource selection function is any function that is proportional to the probability of use of a resource unit (Manly et al. 2002). Resource selection functions have been used to infer habitat quality and their probability of use (Boyce and McDonald 1999) as well as for conservation and management planning (Mysterud and Ims 1999; McDonald 2003; Johnson et al. 2006; Allen et al. 2008). By predicting the probability of habitat use by camels, RSF models have the capacity to be powerful management tools that help allocate resources most effectively and efficiently to manage camel populations.

Generalised linear models (GLMs) have been used to model the habitat associations of a wide range of animals (Guisan and Zimmermann 2000). More recently, generalised additive models (GAMs) have become popular to describe habitat associations and preferences (Elith et al. 2006; Meynard and Quinn 2007). 
GAMs are frequently more flexible than GLMs when the linear predictor can best be described as a sum of smooth functions of covariates plus parametric linear predictors (Wood 2006).

In this paper we use GAMs to analyse the habitat associations of camels in central Australia. Our objectives were to predict the potential distribution and probability of habitat use by feral camels in southern Northern Territory. To make the predictions, we used a range of biotic and non-biotic predictors that were statistically related to locations where camels were observed during the most recent broad-scale aerial survey for camels in the Northern Territory. We then used the predicted habitat associations to identify areas of high cultural and ecological interest that may be heavily impacted by camels.

\section{Materials and methods}

\section{Camel locations}

In 2001, aerial surveys were flown over an area of $260000 \mathrm{~km}^{2}$ of southern Northern Territory. The location of groups of camels along transects was recorded using a GPS connected to a handheld computer. The sampling intensity was $3.6 \%$ of the survey area. Full details of the survey design and results are given by Edwards et al. (2004).

\section{Sample design and habitat associations}

The locations of camels observed during aerial surveys provide information about habitats that camels use, but not about unused habitats, which may be unused because they are avoided or unused simply because there were no camels in the area at the time of the survey. Aerial survey locations represent a snapshot of association between animal and habitat at an instant in time. Using aerial survey data it is not possible to determine preference since there has been no measurement of choice or avoidance (Boyce et al. 2002). Thus, the locations of camels represent 'presenceonly' data. Appropriate analyses characterise habitat association by presence $v$. availability whereby the characteristics of a sample of sites where camels occur is compared with a sample of what is available in the environment (Manly et al. 2002).

We modelled the relationship between camels and the environment by characterising a range of biotic and abiotic covariates (Table 1). The characteristics of 'used' (where camels were observed) $v$. 'unused' (pseudo-absence) sites were compared. The term 'pseudo-absence' is used since it refers to sites where camels were not observed, but this does not imply that those sites were avoided. There were 494 unique groups of camels identified during the aerial survey. An equal number of pseudoabsence sites were chosen. Pseudo-absence sites were chosen randomly without replacement along aerial survey transect lines within the aerial survey block and each site was at least $10 \mathrm{~km}$ from its nearest neighbour (average $18.5 \mathrm{~km}$ ). Used sites were assigned the response variable of 1; unused sites were assigned the response variable 0 .

We hypothesised that camels made decisions regarding their use of a habitat based on resources nearby. Studies of camel movements (Grigg et al. 1995; Edwards et al. 2001) indicated that they will range between $\sim 0.1-30 \mathrm{~km}$ per day, but more commonly $1-10 \mathrm{~km}$ per day. Based on this information, we created two separate buffers around each sample location that we assumed were representative of the spatial scale over which camels made their short-term (i.e. daily to a few days) habitat choices. The buffers were, respectively, 1 and $5 \mathrm{~km}$ in radius, measured from the centre of each site.

The attribute values of covariates were then either based on the value at the centroid of each buffer (elevation and aspect), or the proportion of a covariate within the buffer area (vegetation type) or the nearest-neighbour distance (human population centres, water sources and roads).

\section{Statistical methods}

Following the general method described by Barry and Welsh (2002) for modelling zero inflated count data, we modelled the data in two steps. First, we modelled habitat association using habitat covariates and presence-absence data. Second, we modelled the relationship between abundance and the covariates, conditional on camels being present. The combination of two steps provides a flexible approach to the problem of modelling habitat suitability. The method also provides two predictions: (i) habitat suitability (presence-absence) and (ii) an index of abundance. The latter is only an index because the count data were point estimates of abundance, not density estimates in survey plots.

We modelled camel habitat association and abundance using generalised additive model (GAM) methods in the R statistical computing language ( $\mathrm{R}$ version 2.9.0) ( $\mathrm{R}$ Development Core Team 2008). Early exploratory analyses using GLMs were abandoned when we found they provided low explanatory power in comparison to GAMs. We fitted GAMs using the gam() function from the 'mgcv' package (version 1.5-5) (Wood 2009). For presence-absence, fitted models used a binomial error structure with a logit link. For abundance, fitted models used a Poisson error structure with a log link and a gamma value of 1.4. The gamma value inflates the degrees-of-freedom to help prevent over-fitting (Wood 2006). The best model was chosen by minimising un-biased risk estimator (UBRE). The UBRE score can be interpreted in the same way as AIC (Wood 2006).

\section{Covariates}

Nearest neighbour distance was calculated for human population centres, water sources and roads using GIS (Manifold System 8.0

Table 1. Covariates used to predict camel habitat suitability

\begin{tabular}{llll}
\hline Data type & Covariate & Range & Source \\
\hline Nearest neighbour & Population centres & $0-252 \mathrm{~km}$ & Manifold (www.manifold.net $^{\mathrm{A}}$ ) \\
& Water sources (permanent and ephemeral) & $0-58.8 \mathrm{~km}$ & Manifold (www.manifold.net $^{\mathrm{A}}$ ) \\
& Major and minor roads & $0-165 \mathrm{~km}$ & Manifold (www.manifold.net $^{\mathrm{A}}$ ) \\
Proportion & Vegetation class & (see Table 2) & Wilson et al. (1990) \\
\hline
\end{tabular}

${ }^{A}$ Accessed 11 August 2009. 
Table 2. Vegetation classes used in the model

Classes followed the classifications of Wilson et al. (1990). The percent of the total area of the study site made up by each vegetation class is included

\begin{tabular}{lcr}
\hline Vegetation class & Code & Percent \\
\hline Acacia with grass understorey/Acacia georginae low open woodlands & AC1 & 3.2 \\
Acacia with grass understorey/mixed species low open-woodland & AC3 & 3.4 \\
Acacia with grass understorey/sparse shrubland & AC4 & 4.7 \\
Acacia with grass understorey/tall open shrubland & AC5 & 2.0 \\
Chenopod low sparse-shrub/forbland & CH1 & 2.4 \\
Eucalyptus with grass understorey & EU1 & 4.3 \\
Eucalyptus with hummock grass understorey & EU2 & 15.1 \\
Hummock grassland/mixed species low open-woodland & HU1 & 9.7 \\
Hummock grassland/scattered shrub & HU2 & 0.7 \\
Hummock grassland/tall open-shrubland & HU3 & 54.2 \\
Melaleuca forest/woodland & ME & 0.2 \\
\hline
\end{tabular}

Professional Edition, Build 8.0.12.0) (Table 1). We hypothesised that camels might be attracted to water sources and avoid population centres and roads. The nearest neighbour distance was recorded as the Euclidean distance between the centroid of each used and unused sample location and the closest point in the covariate set.

Using the vegetation classifications (mapping units) described by Wilson et al. (1990), we used 11 simplified vegetation classes (Table 2). Camels were observed at least once in each class. The value of each vegetation class was calculated as the proportion of the total buffer area made up by each class.

Several climate variables, including temperature (mean annual, mean summer, maximum summer and minimum winter) and rainfall (mean annual and mean summer) were tested during preliminary model fitting and found to be unrelated to camel distribution. A range of topographic variables (elevation, slope and aspect) were also trialled and found to be unrelated to camel distribution.

\section{Evaluation of predictive performance}

Ideally, the predictive performance of the models would be tested using an independent data source. In the absence of independent data we evaluated the predictive performance of the models by internal validation using k-fold cross-validation (Kohavi 1995), with 10 folds. The details of the method are presented by Cowled et al. (2009).

Briefly, models were evaluated using the area under the receiver operator characteristic (ROC) curve (Pearce and Ferrier 2000; Wintle et al. 2005). The area under the ROC curve (AUC) is a measure of the model's ability to correctly distinguish between presence and absence. Thus, it is referred to as a measure of model discrimination (Pearce and Ferrier 2000). The statistic can be interpreted in a straightforward manner; a value of 1 indicates perfect discrimination, whereas a value of 0.5 indicates that the model performs no better than a random guess (Fawcett 2006). Swets (1988) considered values above 0.7 provided reasonable discrimination and the larger the AUC the better the model at predicting group membership. Calculation of AUC used the auc () function in the PresenceAbsence package (version 1.1.3) in $\mathrm{R}$ (Freeman 2007).

\section{Predicting habitat suitability and relative abundance}

Using the best overall models for each buffer we determined the habitat suitability and abundance for each point in Fig. 1. The predicted index of abundance was calculated from the product of

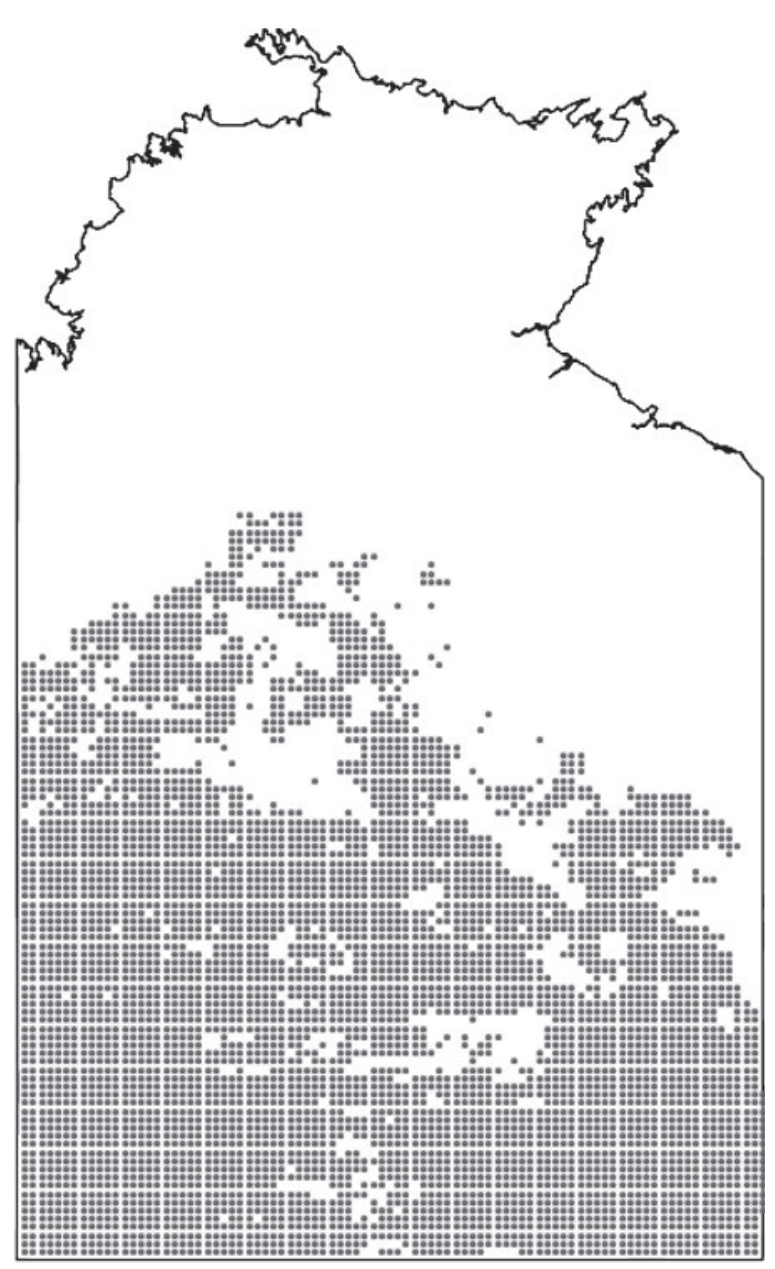

Fig. 1. Point locations for which camel habitat covariate values were measured. 
the probability estimate from the presence-absence model and the modelled abundance (Barry and Welsh 2002). We used simple kriging with eight nearest neighbours to create smooth surfaces of predicted camel habitat suitability and relative abundance. These surfaces are estimates of the potential habitat suitability and abundance of camels in southern Northern Territory at the time of the survey.

\section{Areas of importance}

Using GIS, we overlaid the predicted habitat suitability maps on a map that included areas of indigenous, natural and historic significance recorded on the Register of the National Estate (RNE). The intersection of areas of high habitat suitability and RNE significance indicates potential priority regions for camel management.

Table 3. Significance of smooth and parametric model terms in the presence-absence model based on a $1 \mathrm{~km}$ buffer

$\mathrm{s}$ (lat, lon) is the smoothed model term representing location (latitude and longitude), s(popn) is the term representing distance from centres of population, $\mathrm{s}(\operatorname{tran})$ is the term representing distance from roads, and EU2 and HU1 are parametric terms representing vegetation classes (see Table 2). The model had an un-biased risk estimator (UBRE) score of 0.0758 . The parametric term EU2 was included in the model since it was correlated with other model variables and resulted in a higher UBRE score if it was deleted

\begin{tabular}{lrcl}
\hline Model terms & Df/edf & Chi-square & $P$-value \\
\hline s(lat, lon) & 131.223 & 239.69 & $2.35 \mathrm{e}-08$ \\
s(popn) & 5.252 & 62.04 & $6.50 \mathrm{e}-12$ \\
s(tran) & 4.550 & 41.03 & $5.36 \mathrm{e}-08$ \\
EU2 & 1 & 2.884 & 0.0895 \\
HU1 & 1 & 23.565 & $1.21 \mathrm{e}-06$ \\
\hline
\end{tabular}

Table 4. Significance of smooth and parametric model terms in the presence-absence model based on a $5 \mathrm{~km}$ buffer

$\mathrm{s}$ (lat, lon) is the smoothed model term representing location (latitude and longitude), s(popn) is the term representing distance from centres of population, $\mathrm{s}(\mathrm{tran})$ is the term representing distance from roads, and $\mathrm{AC} 3$, AC4, AC5, CH1, EU1, EU2, HU1, HU2 and HU3 are parametric terms representing vegetation classes (see Table 2). The model had an un-biased risk estimator (UBRE) score of 0.0693 . The parametric term EU1 was included in the model since it was correlated with other model variables and resulted in a higher UBRE score if it was deleted

\begin{tabular}{lrcc}
\hline Model terms & Df/edf & Chi-square & $P$-value \\
\hline s(lat, lon) & 126.0 & 229.51 & $4.94 \mathrm{e}-08$ \\
s(popn) & 5.47 & 64.69 & $2.47 \mathrm{e}-12$ \\
s(tran) & 4.47 & 37.80 & $2.22 \mathrm{e}-07$ \\
AC3 & 1 & 6.282 & 0.01220 \\
AC4 & 1 & 7.697 & 0.00553 \\
AC5 & 1 & 8.895 & 0.00286 \\
CH1 & 1 & 7.344 & 0.00673 \\
EU1 & 1 & 3.041 & 0.08120 \\
EU2 & 1 & 10.524 & 0.00118 \\
HU1 & 1 & 10.819 & 0.00100 \\
HU2 & 1 & 7.270 & 0.00701 \\
HU3 & 1 & 7.329 & 0.00679 \\
\hline
\end{tabular}

\section{Results}

\section{Habitat suitability}

The predicted habitat suitability surfaces indicate areas of suitable habitat for camels. For the $1 \mathrm{~km}$ buffer the model selected was:

$$
\begin{aligned}
\eta= & s(\text { latitude }, \text { longitude }) \\
& +\mathrm{s}(\text { distance from population centres }) \\
& +\mathrm{s}(\text { distance from roads })+\mathrm{EU} 2+\mathrm{HU} 1
\end{aligned}
$$

where $\eta$ is the probability of occurrence and $s()$ is a smooth function. The model explained $43.4 \%$ of the deviance. The statistical significance of parametric and smooth model terms is presented in Table 3. An explanation of the parametric terms is presented in Table 2 .
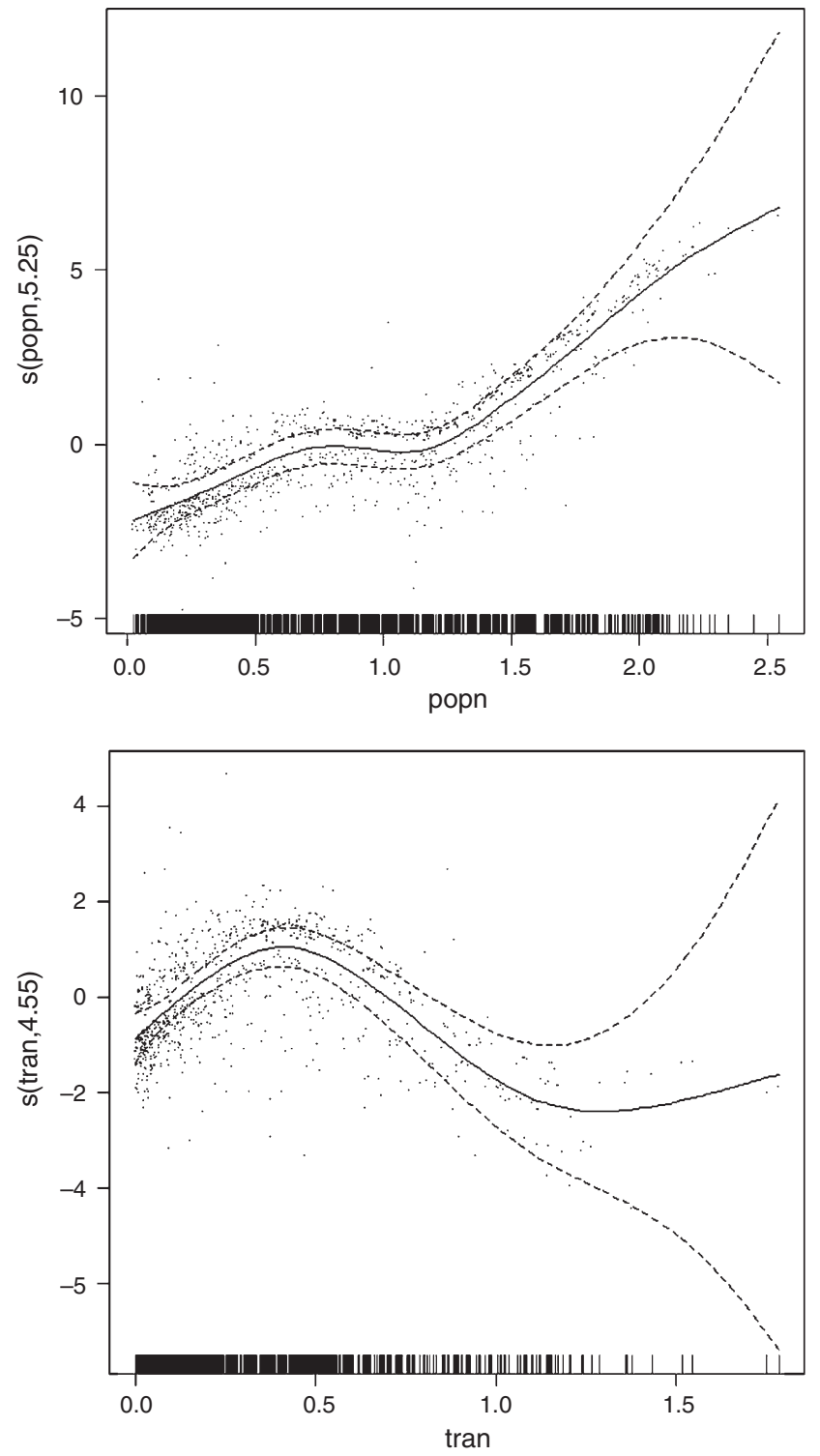

Fig. 2. Smoothed fits to the covariates distance to population centres (popn) and distance to roads (tran) used in the final habitat suitability model with a $1 \mathrm{~km}$ buffer. Dashed lines give $\sim 95 \%$ confidence intervals. The units of the $x$-axis are decimal degrees. 
For the $5 \mathrm{~km}$ buffer, the model selected was:

$$
\begin{aligned}
\eta= & \mathrm{s}(\text { latitude }, \text { longitude }) \\
& +\mathrm{s}(\text { distance from population centres }) \\
& +\mathrm{s}(\text { distance from roads })+\mathrm{AC} 3+\mathrm{AC} 4+\mathrm{AC} 5 \\
& +\mathrm{CH} 1+\mathrm{EU} 1+\mathrm{EU} 2+\mathrm{HU} 1+\mathrm{HU} 2+\mathrm{HU} 3
\end{aligned}
$$

where $\eta$ is the probability of occurrence and $s()$ is a smooth function. The model explained $44.2 \%$ of the deviance. The statistical significance of parametric and smooth model terms is presented in Table 4. An explanation of the parametric terms is presented in Table 2.

The differences between these two models was the inclusion of a large number of vegetation categories in the $5 \mathrm{~km}$ buffer model, which were absent from the $1 \mathrm{~km}$ buffer model. The most likely reason would be the substantial increase in area of the $5 \mathrm{~km}$ buffer relative to the $1 \mathrm{~km}$ buffer. Consequently, the buffer area from the $5 \mathrm{~km}$ buffer intersected with a greater range of vegetation classes.
The smooth terms latitude, longitude, distance to population centres and distance to roads were common to both models. Examples of smoothed fits to the covariates distance to population centres and distance to roads are given in Fig. 2. The fitted splines indicate that the probability of presence of camels increases with distance from either a population centre or a road, but with probability of presence declining at large distances from roads.

The significance of the terms for smoothed latitude and longitude in the models reflects some of the (2-dimensional) spatial variation in occupancy that has not been captured by the environmental covariates. Locations can only be a proxy for biologically important variables, and they are included in the model because they are correlated with some underlying process.

The largest difference in the predicted habitat suitability surfaces occurs on the eastern sector (Figs 3,4). The model based on a $5 \mathrm{~km}$ buffer included extensive areas in the east that ranked as medium-high suitable habitat. These areas contained Acacia with grass understorey and Acacia georginae low open woodlands (AC1, Table 2).

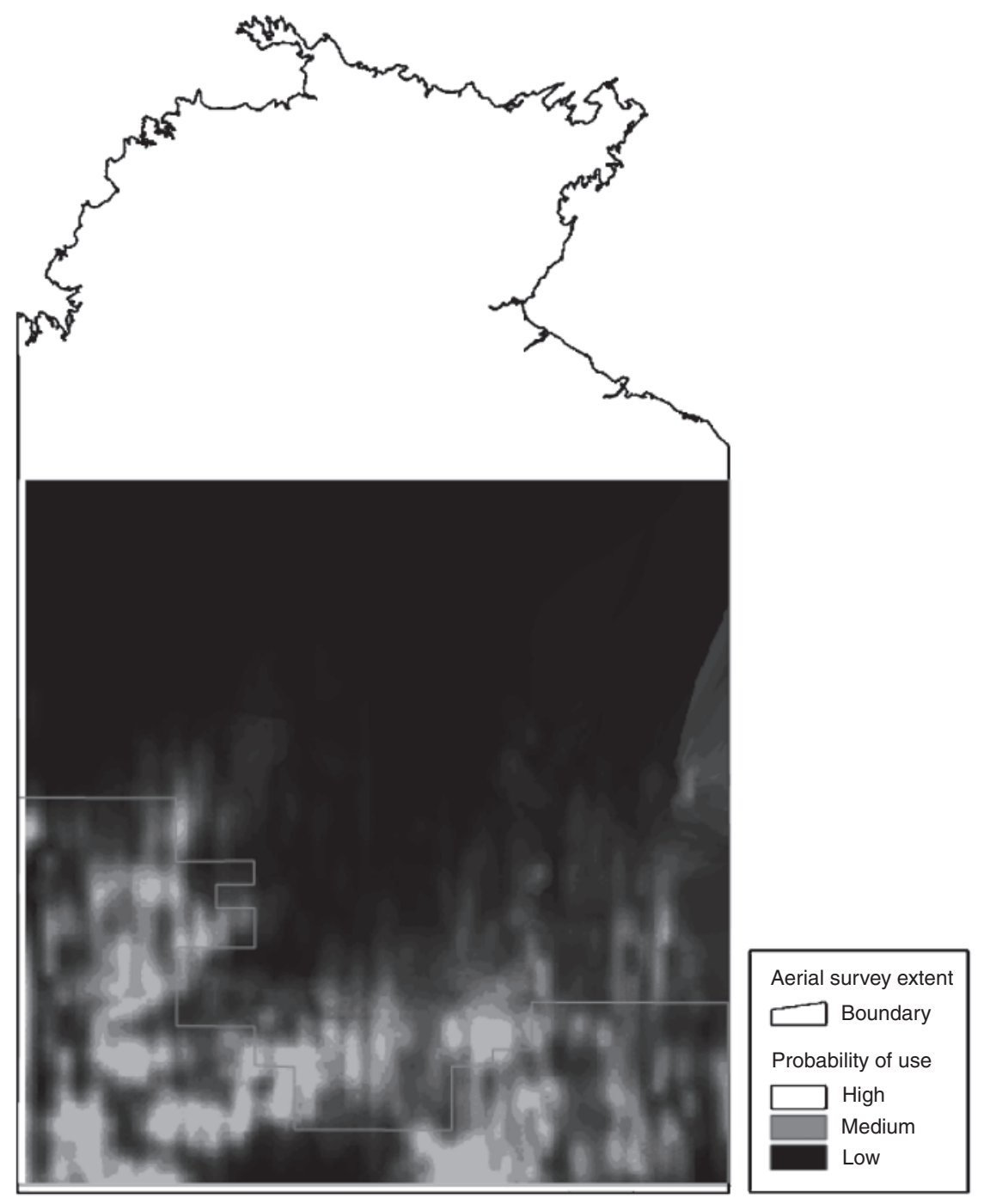

Fig. 3. Predicted camel habitat suitability based on a $1 \mathrm{~km}$ buffer around sample locations. The extent of the aerial survey conducted in 2001 by Edwards et al. (2004) is also shown on the map. 


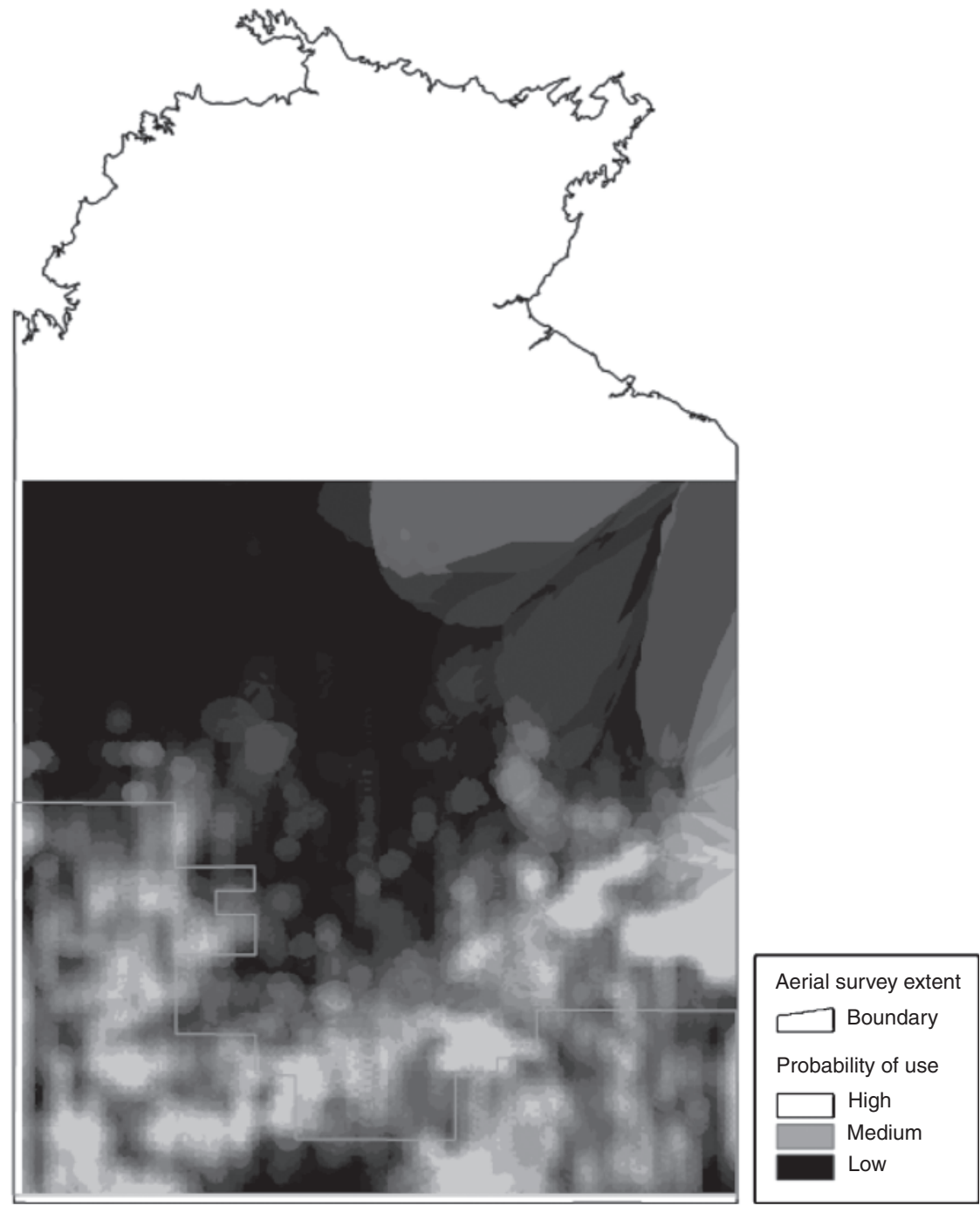

Fig. 4. Predicted camel habitat suitability based on a $5 \mathrm{~km}$ buffer around sample locations. The extent of the aerial survey conducted in 2001 by Edwards et al. (2004) is also shown on the map.

The habitat suitability surfaces indicated that the majority of southern Northern Territory is predicted to be suitable for camels.

\section{Relative abundance}

There was no difference in the structure of the best models fitted to the count data. For both the $1 \mathrm{~km}$ and $5 \mathrm{~km}$ buffers the selected model was:

$$
\begin{aligned}
\eta= & \mathrm{s}(\text { latitude, longitude })+\mathrm{s}(\text { distance from water }) \\
& +\mathrm{AC} 1+\mathrm{AC} 3+\mathrm{AC} 4+\mathrm{AC} 5+\mathrm{CH} 1 \\
& +\mathrm{EU} 1+\mathrm{HU} 1+\mathrm{HU} 3
\end{aligned}
$$

where $\eta$ is the camel abundance and $s()$ is a smooth function (Tables 5 and 6). An explanation of the parametric terms is presented in Table 2. The fitted models explained 69 and $71.6 \%$ of the deviance in the data for the 1 and $5 \mathrm{~km}$ buffers, respectively. The predicted count surfaces (Figs 5,6) indicate that there are a few 'hotspots' of camel abundance. Keeping in mind that the predicted abundance surfaces are the product of the predictions of the presence-absence model and the count model, the surfaces are remarkably similar. Also, the region to the east that was of medium-high suitability is not predicted to sustain a high abundance of camels.

The predicted abundance surface indicates that camels will probably occur at low density across southern Northern Territory and occasionally reach very high density. However, these 'hotspots' of abundance cover on average $\sim 1000 \mathrm{~km}^{2}$ and biodiversity impacts by camels over such a large area can be substantial (Edwards et al. 2008).

Hotspots coincided with a wide range of vegetation classes including Acacia with grass understorey/sparse shrubland (AC4), Acacia with grass understorey/tall open shrubland (AC5), chenopod low sparse-shrub/forbland (CH1), Acacia with grass understorey/Acacia georginae low open woodlands (AC1), hummock grassland/tall open-shrubland (HU3) and hummock grassland/mixed species low open-woodland (HU1). These vegetation types are widespread across southern Northern 
Table 5. Significance of smooth and parametric model terms in the count model based on a $1 \mathrm{~km}$ buffer

$\mathrm{s}$ (lat, lon) is the smoothed model term representing location (latitude and longitude), $\mathrm{s}$ (water) is the term representing distance from water sources, and $\mathrm{AC} 1, \mathrm{AC} 3, \mathrm{AC} 4, \mathrm{AC} 5, \mathrm{CH} 1, \mathrm{EU} 1, \mathrm{HU} 1$ and $\mathrm{HU} 3$ are parametric terms representing vegetation classes (see Table 2). The model had un-biased risk estimator (UBRE) score of 1.566. The parametric terms AC3 and HU1 were included in the model since they were correlated with other model covariates and deleting them resulted in a higher UBRE score

\begin{tabular}{lrcl}
\hline Model terms & Df/edf & Chi-square & $P$-value \\
\hline s(lat, lon) & 165.801 & 227.44 & 0.00106 \\
s(water) & 8.745 & 35.62 & $3.79 \mathrm{e}-05$ \\
AC1 & 1 & 5.480 & 0.01924 \\
AC3 & 1 & 0.723 & 0.39513 \\
AC4 & 1 & 4.896 & 0.02691 \\
AC5 & 1 & 7.080 & 0.00779 \\
CH1 & 1 & 5.628 & 0.01768 \\
EU1 & 1 & 7.505 & 0.00615 \\
HU1 & 1 & 2.942 & 0.08632 \\
HU3 & 1 & 5.620 & 0.01775 \\
\hline
\end{tabular}

Table 6. Significance of smooth and parametric model terms in the count model based on a $5 \mathrm{~km}$ buffer

$\mathrm{s}$ (lat, lon) is the smoothed model term representing location (latitude and longitude), $\mathrm{s}$ (water) is the term representing distance from water sources, and $\mathrm{AC} 1, \mathrm{AC} 3, \mathrm{AC} 4, \mathrm{AC} 5, \mathrm{CH} 1, \mathrm{EU} 1, \mathrm{HU} 1$ and $\mathrm{HU} 3$ are parametric terms representing vegetation classes (see Table 2). The model had un-biased risk estimator un-biased risk estimator (UBRE) score of 1.470. The parametric terms EU1 and HU1 were included in the model since they were correlated with other model covariates and deleting them resulted in a higher UBRE score

\begin{tabular}{lrcc}
\hline Model terms & Df/edf & Chi-square & $P$-value \\
\hline s(lat, lon) & 172.0 & 283.75 & $1.58 \mathrm{e}-07$ \\
s(water) & 8.66 & 36.96 & $2.03 \mathrm{e}-05$ \\
AC1 & 1 & 2.497 & 0.11403 \\
AC3 & 1 & 10.654 & 0.00110 \\
AC4 & 1 & 5.796 & 0.01607 \\
AC5 & 1 & 7.018 & 0.00807 \\
CH1 & 1 & 6.763 & 0.00931 \\
EU1 & 1 & 1.042 & 0.30745 \\
HU1 & 1 & 2.446 & 0.11786 \\
HU3 & 1 & 7.308 & 0.00686 \\
\hline
\end{tabular}

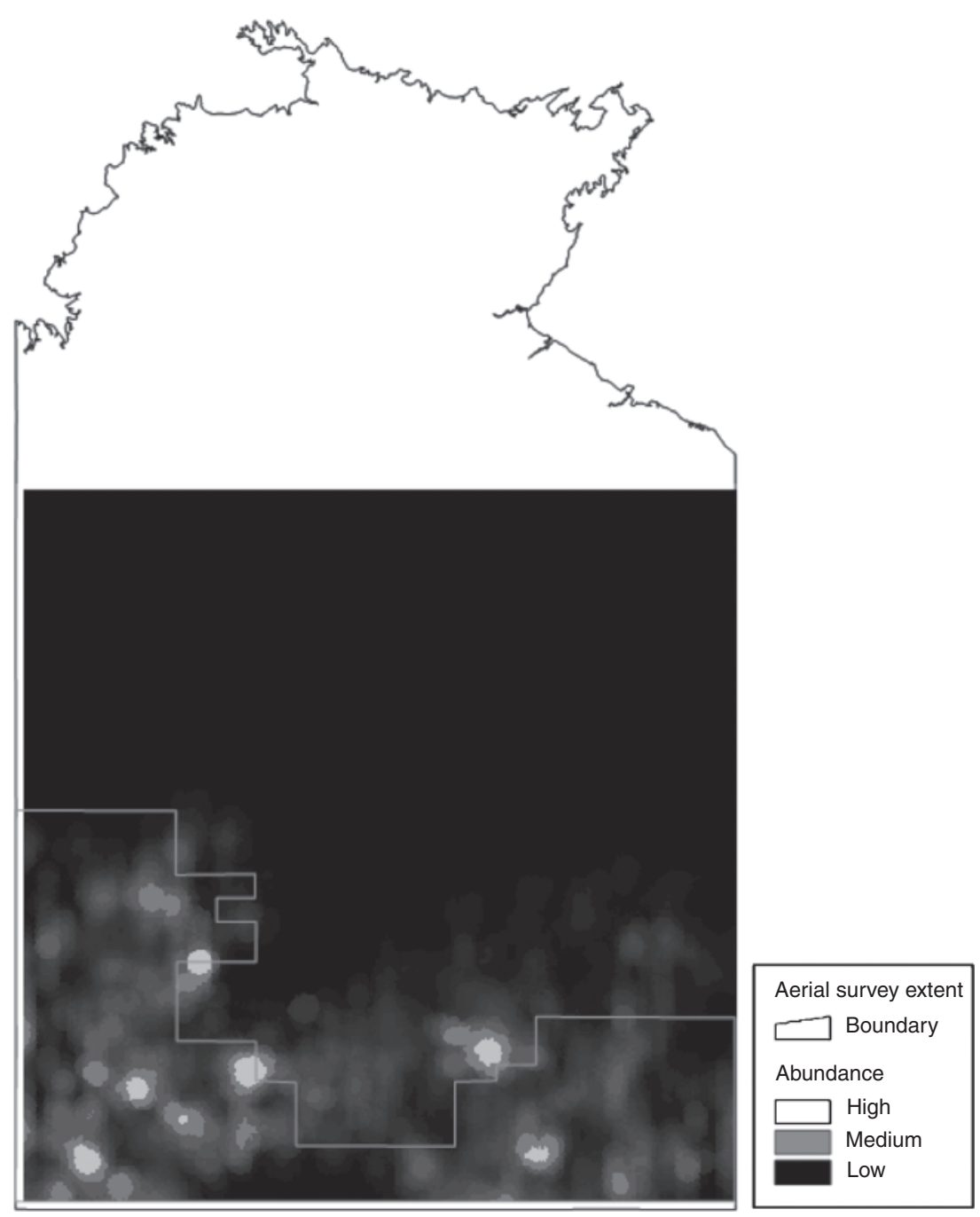

Fig. 5. Predicted abundance of camels based on a $1 \mathrm{~km}$ buffer around sample locations. The extent of the aerial survey conducted in 2001 by Edwards et al. (2004) is also shown on the map. 


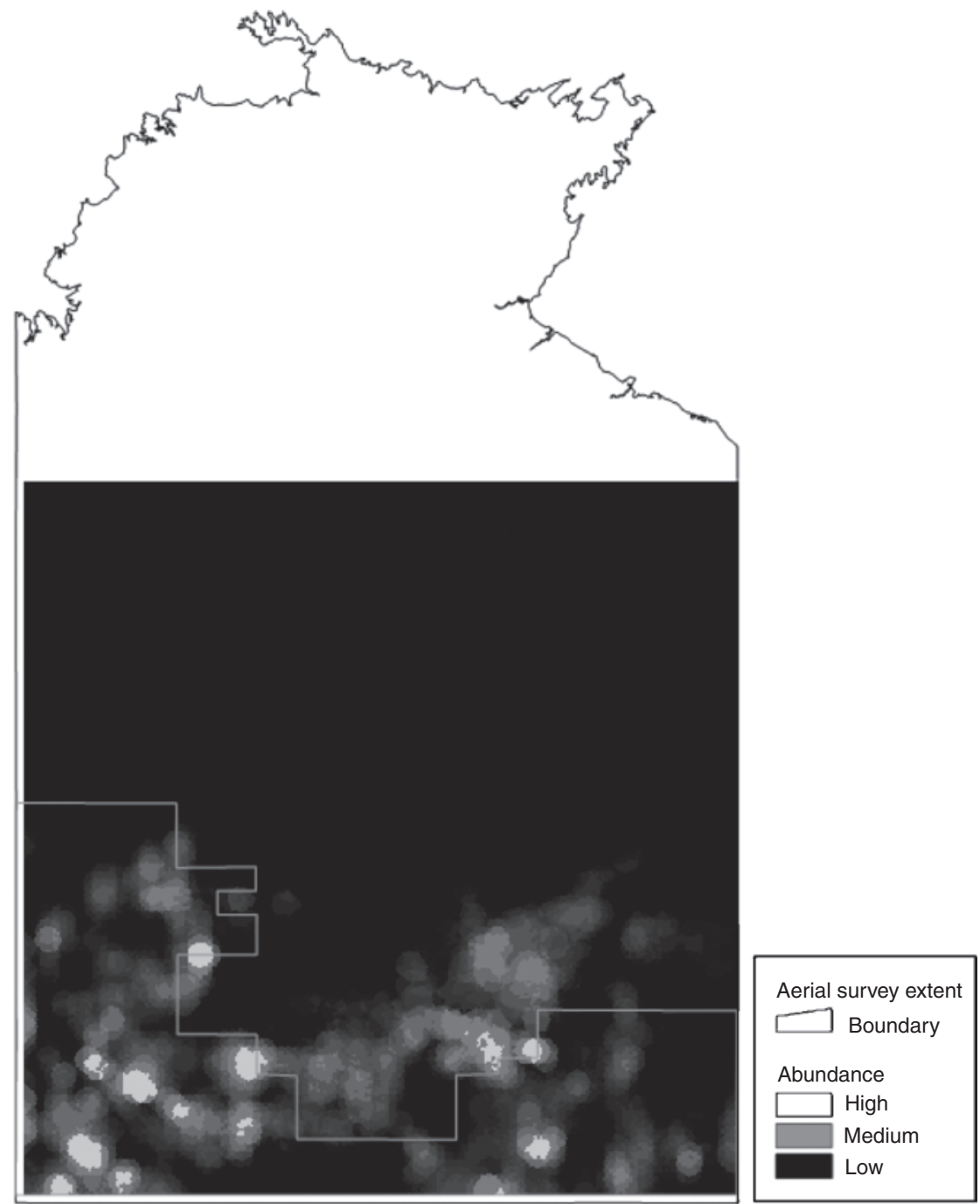

Fig. 6. Predicted abundance of camels based on a $5 \mathrm{~km}$ buffer around sample locations. The extent of the aerial survey conducted in 2001 by Edwards et al. (2004) is also shown on the map.

Territory and may indicate why camels have been so successful in this region.

\section{Evaluation of predictive performance}

The AUC values for the 1 and $5 \mathrm{~km}$ buffers were 0.77 and 0.79 , respectively. The slightly higher value for the $5 \mathrm{~km}$ buffer model indicates slightly better cross-validation agreement between the predicted and observed presence-absence data, but this difference is still small. Following the classification described by Hosmer and Lemeshow (2000) the level of predictive ability for these models is 'acceptable', but keeping in mind that values greater than 0.8 are 'excellent' the models are at the right end of 'acceptable'.

\section{Areas of importance}

Given that suitable habitats for camels are widespread in southern Northern Territory it is not surprising that there are substantial areas of natural and indigenous significance that are at risk.
Of particular concern is the south-eastern region that includes the Simpson Desert (Figs 7, 8). This is a large area of natural significance that contains large regions of suitable habitat for camels. Fortuitously, the region does not include many hotspots of predicted high abundance. Nevertheless, given the logistical difficulties controlling camels in remote locations it will probably be difficult to manage camels in this region. Areas of significance that coincide with hotspots in the south-west include Lake Amadeus, Watarrka (Kings Canyon) National Park, the George Gill Range and Finke Gorge National Park.

\section{Discussion}

The predicted habitat suitability surfaces indicate that highly suitable habitats for camels are widespread across southern Northern Territory. However, with the exception of the southwest region, these areas did not have very high numbers of camels in 2001 (Edwards et al. 2004). It may be difficult to limit the immigration of camels following control operations owing to 


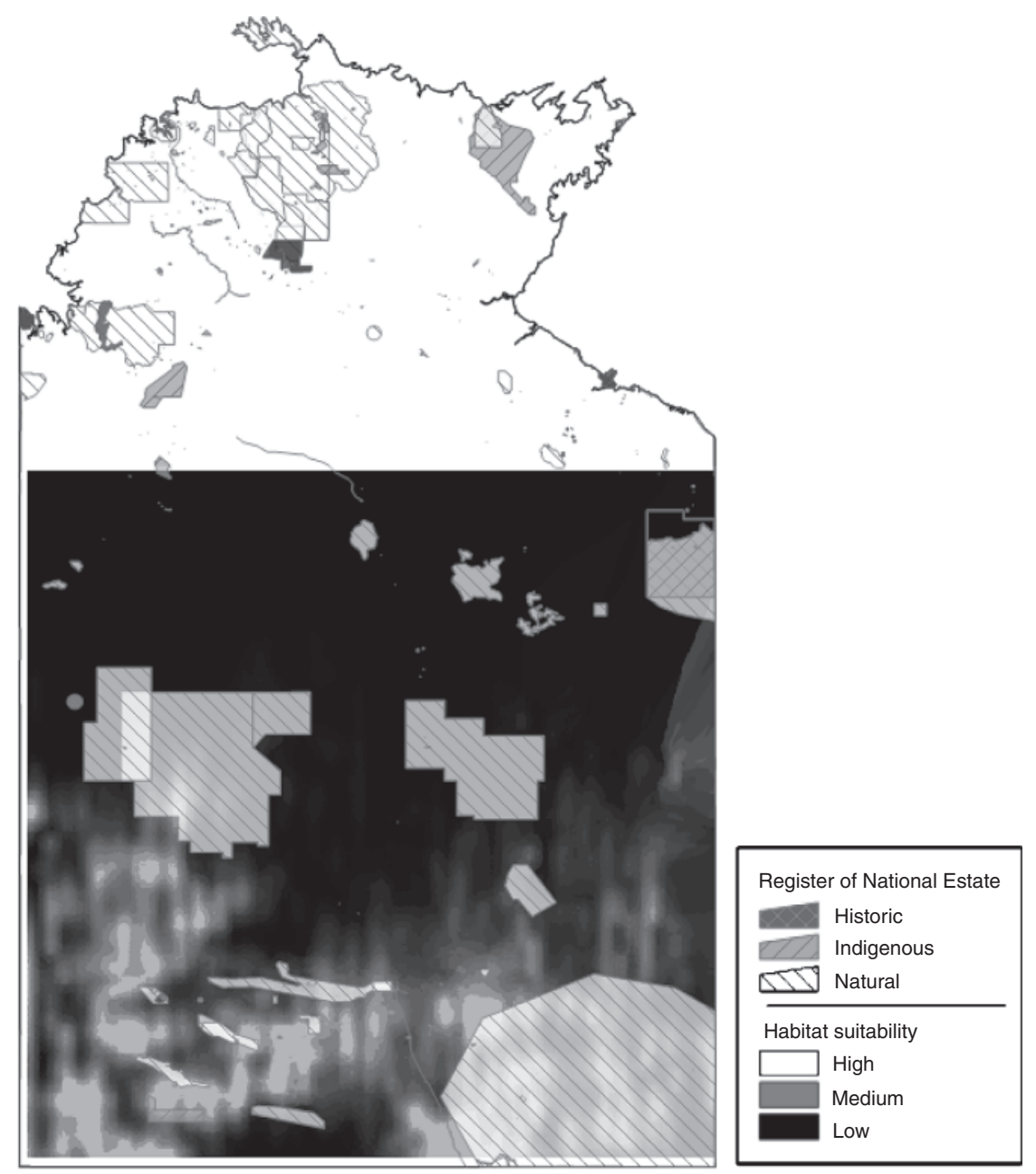

Fig. 7. Overlap between areas of significance on the Register of National Estate and camel habitat suitability based on a $1 \mathrm{~km}$ buffer around sample locations.

their ability to move quickly over large distances (Grigg et al. 1995; Edwards et al. 2001; Saalfeld and Edwards 2008) and the widespread availability of suitable habitat in southern Northern Territory. However, the predicted suitability and abundance surfaces are based on surveys that had low sampling intensity and camels were at low density. This combination may have conspired to provide a deceptive picture of camel distribution.

Discrepancies between predicted habitat suitability and abundance and observed distribution may be due to the fact that camels are not near carrying capacity in the Northern Territory. Camel populations are still growing at, or close to, their maximum rate (Pople and McLeod 2010) and it may take many more years until some type of equilibrium is reached between camel abundance and the environment. Even at low density, camels can have damaging impacts and holding the long-term density to the recommended level of $0.1-0.2$ camels $/ \mathrm{km}^{2}$ (Edwards et al. 2008) will pose a difficult challenge. Given the large areas of suitable habitat for camels, planning of management will be hindered without more up-to-date information regarding their current distribution and abundance.
Errors in either the model, such as important covariates not being included, or data, such as misidentification of true absence, can lead to prediction errors (Fielding and Bell 1997; Barry and Elith 2006). For example, normalised difference vegetation index (NDVI), which measures live green vegetation (Schowengerdt 2007), has been used as a proxy for plant productivity and habitat quality of ungulates (e.g. Verlinden and Masogo 1997; Pettorelli et al. 2006) and birds (e.g. Osborne et al. 2001). Green vegetation may be an important influence on the distribution of camels that are able to move large distances in search of food (Iqbal and Khan 2001). Unfortunately, we were unable to obtain NDVI for the time of the aerial survey. The models presented in this paper make specific predictions regarding the suitability of habitat and relative abundance of camels in the Northern Territory at the time of the survey in 2001. It would be timely to conduct additional surveys to determine current camel density in specific habitats and validate this model and collect data on other co-variates, such as NDVI, which may be important predictors of camel distribution and abundance.

Latitude and longitude were important predictors of camel habitat association and abundance. It is very unlikely that location 


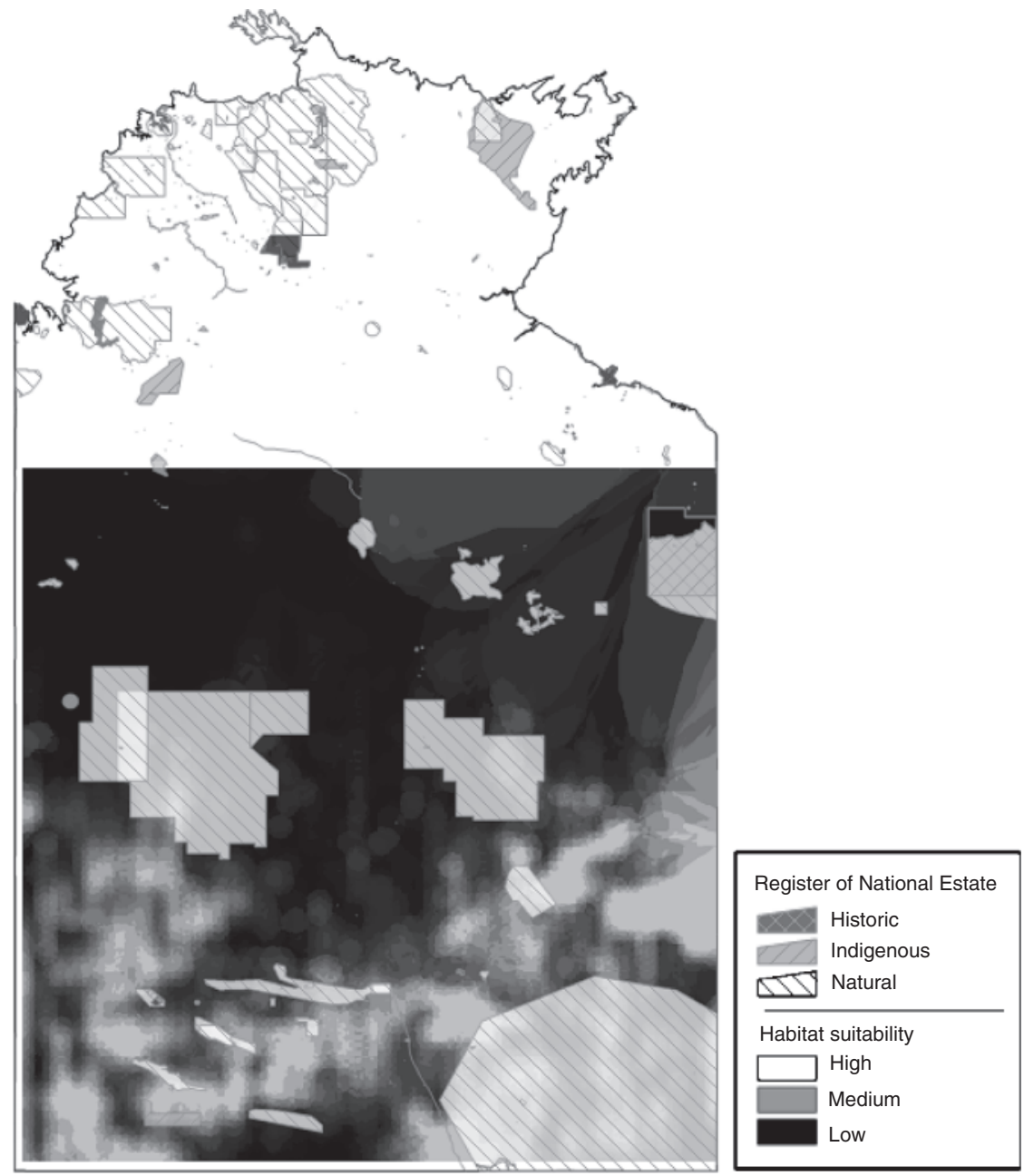

Fig. 8. Overlap between areas of significance on the Register of National Estate and camel habitat suitability based on a $5 \mathrm{~km}$ buffer around sample locations.

per se would be an important determinant of habitat association. Rather, location is likely to be correlated with important variables that influence habitat suitability. Although we examined a range of climate variables likely to be correlated with latitude and longitude, none were significantly related to the observed distribution of camels. This result highlights our general lack of knowledge regarding the ecology of wild camels in Australia. Increased knowledge of the most important factors influencing their rate of increase are likely to provide a much more focused method of selecting variables that influence distribution. It will also lead to greater generality of the predictions of the models.

Until more information regarding the physiology and ecology of camels becomes available and we can make predictions without the use of explicit spatial variables, such as latitude and longitude, there remains a caveat on the predictions: the model's predictions outside of surveyed areas are unreliable. However, within surveyed areas the predictions of the model were robust to cross-validation and can be considered to be valid.

There have been suggestions that commercial use of camels may be a useful form of control (Zeng and McGregor 2008).
However, commercial use of wildlife requires infrastructure for harvested animals to be held, handled and transported from often remote field locations. In addition, the profitability of commercial enterprises is improved by camels being at high density. The analysis of habitat suitability and relative abundance indicated that many suitable habitats and areas of potentially high relative abundance are large distances from the necessary infrastructure, such as roads and population centres. The models of relative abundance predict that camels will occur at low density across most of southern Northern Territory. In combination, these factors are likely to reduce profitability and might make commercial use nonviable in many areas.

The management of camels in Central Australia poses unique problems, the solutions to which are not clear. Camels can have large impacts even when they are at low density (Edwards et al. 2008) and they are difficult and costly to manage (Drucker 2008). The habitat suitability maps derived in the present study indicate that camels have suitable habitat in most areas of southern Northern Territory. Maps of suitable habitats and abundance can play a major role in strategic approach to managing camels and 
their impacts. However, to maximise their usefulness we need better information on the ecology of camels so that these maps can be refined and generalised.

\section{Acknowledgements}

We would like to thank Glenn Edwards, Keith Saalfeld, Kathy McConnell and Peter West for providing data and Peter Whitehead for providing comments on a draft. The work reported in this publication is supported by funding from the Australian Government Natural Heritage Trust through the Desert Knowledge $\mathrm{CRC}$; the views expressed herein do not necessarily represent the views of the Australian Government or the Desert Knowledge CRC or its participants.

\section{References}

Allen, J. R., McInenly, L. E., Merrill, E. H., and Boyce, M. S. (2008). Using resource selection functions to improve estimation of elk population numbers. Journal of Wildlife Management 72, 1798-1804. doi:10.2193/ 2007-311

Barry, S., and Elith, J. (2006). Error and uncertainty in habitat models. Journal of Applied Ecology 43, 413-423. doi:10.1111/j.1365-2664.2006.01136.x

Barry, S. C., and Welsh, A. H. (2002). Generalized additive modelling and zero inflated count data. Ecological Modelling 157, 179-188. doi:10.1016/S0304-3800(02)00194-1

Boyce, M. S., and McDonald, L. L. (1999). Relating populations to habitats using resource selection functions. Trends in Ecology \& Evolution 14, 268-272. doi:10.1016/S0169-5347(99)01593-1

Boyce, M. S., Vernier, P. R., Nielsen, S. E., and Schmiegelow, F. K. A. (2002). Evaluating resource selection functions. Ecological Modelling 157, 281-300. doi:10.1016/S0304-3800(02)00200-4

Cowled, B. D., Giannini, F., Beckett, S. D., Woolnough, A., Barry, S., Randall, L., and Garner, G. (2009). Feral pigs: predicting future distributions. Wildlife Research 36, 242-251. doi:10.1071/WR08115

Drucker, A. G. (2008). Economics of feral camel control in the central region of the Northern Territory. In: 'Managing The Impacts of Feral Camels in Australia: A New Way of Doing Business'. DKCRC Report 47. (Eds G. P. Edwards, B. Zeng, W. K. Saalfeld, P. Vaarzon-Morel and M. McGregor.) (Desert Knowledge Cooperative Research Centre: Alice Springs.)

Edwards, G. P., Eldridge, S. R., Wurst, D., Berman, D. M., and Garbin, V. (2001). Movement patterns of female feral camels in central and northern Australia. Wildlife Research 28, 283-289. doi:10.1071/WR00053

Edwards, G. P., Saalfeld, K., and Clifford, B. (2004). Population trend of feral camels in the Northern Territory. Australian Wildife Research 31, 509-517. doi:10.1071/WR03073

Edwards, G. P., Zeng, B., and Saalfeld, W. K. (2008). Evaluation of the impacts of feral camels. In: 'Managing the Impacts of Feral Camels in Australia: a New Way of Doing Business'. DKCRC Report 47. (Eds G. P. Edwards, M. McGregor, B. Zeng, P. Vaarzon-Morel and W. K. Saalfeld.) (Desert Knowledge Cooperative Research Centre: Alice Springs.)

Elith, J., Graham, C. H., Anderson, R. P., Dudík, M., Ferrier, S., Guisan, A., Hijmans, R. J., Huettmann, F., Leathwick, J. R., Lehmann, A., Li, J., Lohmann, L. G., Loiselle, B. A., Manion, G., Moritz, C., Nakamura, M., Nakazawa, Y., Overton, J. McC. M., Peterson, A. T., Phillips, S. J., Richardson, K., Scachetti-Pereira, R., Schapire, R. E., Soberón, J., Williams, S., Wisz, M. S., and Zimmermann, N. E. (2006). Novel methods improve prediction of species' distributions from occurrence data. Ecography 29, 129-151. doi:10.1111/j.2006.0906-7590.04596.x

Fawcett, T. (2006). An introduction to ROC analysis. Pattern Recognition Letters 27, 861-874. doi:10.1016/j.patrec.2005.10.010

Fielding, A. H., and Bell, J. F. (1997). A review of methods for the assessment of prediction errors in conservation presence/absence models. Environmental Conservation 24, 38-49. doi:10.1017/S03768 92997000088
Freeman, E. (2007). 'PresenceAbsence: an R Package for Presence-Absence Model Evaluation.' (USDA Forest Service: Rocky Mountain Research Station, Ogden, UT.)

Grigg, G. C., Pople, A. R., and Beard, L. A. (1995). Movements of feral camels in central Australia determined by satellite telemetry. Journal of Arid Environments 31, 459-469. doi:10.1016/S0140-1963 (05)80129-6

Guisan, A., and Thuiller, W. (2005). Predicting species distribution: offering more than simple habitat models. Ecology Letters 8, 993-1009. doi:10.1111/j.1461-0248.2005.00792.x

Guisan, A., and Zimmermann, N. E. (2000). Predictive habitat distribution models in ecology. Ecological Modelling 135, 147-186. doi:10.1016/ S0304-3800(00)00354-9

Hosmer, D. W., and Lemeshow, S. (2000). 'Applied Logistic Regression.' (John Wiley \& Sons: New York.)

Iqbal, A., and Khan, B. B. (2001). Feeding behaviour of camel: a review. Pakistan Journal of Agricultural Science 38, 58-63.

Johnson, C. J., Nielsen, S. E., Merrill, E. H., McDonald, T. L., and Boyce, M. S. (2006). Resource selection functions based on use-availability data: theoretical motivation and evaluation methods. The Journal of Wildife Management 70, 347-357. doi:10.2193/0022-541X(2006)70 [347:RSFBOU]2.0.CO;2

Kohavi, R. (1995). A study of cross-validation and bootstrap for accuracy estimation and model selection. In: 'Proceedings of the 14th International Joint Conference on Artificial Intelligence'. (Ed. C. S. Mellish.) pp. 1137-1143. (Morgan Kaufmann: San Mateo, CA.)

Larson, M. A., Millspaugh, J. J., and Thompson, F. R. III (2008). A review of methods for quantifying wildlife habitat in large landscapes. In: 'Models for Planning Wildlife Conservation in Large Landscapes'. (Eds J. J. Millspaugh and F. R. Thompson, III.) pp. 225-250. (Academic Press: San Diego, CA.)

Manly, B. F. J., McDonald, L. L., Thomas, D. L., McDonald, T. L., and Erickson, W. P. (2002). 'Resource Selection by Animals: Statistical Design and Analysis for Field Studies.' (Kluwer Academic Publishers: Boston.)

McDonald, T. L. (2003). Estimation of resource selection functions when used and available samples overlap. In: 'Proceedings of the First International Conference on Resource Selection'. pp. 35-39. (Laramie: WY.)

Meynard, C. N., and Quinn, J. F. (2007). Predicting species distributions: a critical comparison of the most common statistical models using artificial species. Journal of Biogeography 34, 1455-1469. doi:10.1111/ j.1365-2699.2007.01720.x

Mysterud, A., and Ims, R. A. (1999). Relating populations to habitats. Trends in Ecology \& Evolution 14, 489-490. doi:10.1016/S0169-5347 (99)01713-9

Osborne, P. E., Alonso, J. C., and Bryant, R. G. (2001). Modelling landscapescale habitat use using GIS and remote sensing: a case study with great bustards. Journal of Applied Ecology 38, 458-471. doi:10.1046/j.13652664.2001.00604.x

Pearce, J., and Ferrier, S. (2000). An evaluation of alternative algorithms for fitting species distribution models using logistic regression. Ecological Modelling 128, 127-147. doi:10.1016/S0304-3800(99)00227-6

Pettorelli, N., Gaillard, J.-M., Mysterud, A., Duncan, P., Stenseth, N. C., Delorme, D., Laere, G. V., Toïgo, C., and Klein, F. (2006). Using a proxy of plant productivity (NDVI) to find key periods for animal performance: the case of roe deer. Oikos 112, 565-572. doi:10.1111/j.00301299.2006.14447.x

Pople, A. R., and McLeod, S. R. (2010). Demography of feral camels in central Australia and its relevance to population control. The Rangeland Journal 32, 11-19.

R Development Core Team (2008). 'R: A language and environment for statistical computing.' (R Foundation for Statistical Computing: Vienna.) Available at: www.R-project.org 
Saalfeld, W. K., and Edwards, G. P. (2008). Ecology of feral camels in Australia. In: 'Managing the Impacts of Feral Camels in Australia: A New Way of Doing Business'. DKCRC Report 47. (Eds G. P. Edwards, B. Zeng, W. K. Saalfeld, P. Vaarzon-Morel and M. McGregor.) (Desert Knowledge Cooperative Research Centre: Alice Springs.)

Schowengerdt, R. A. (2007). 'Remote Sensing: Models and Methods for Image Processing.' 3rd edn. (Academic Press: Burlington, MA.)

Swets, J. A. (1988). Measuring the accuracy of diagnostic systems. Science 240, 1285-1293. doi:10.1126/science. 3287615

Verlinden, A., and Masogo, R. (1997). Satellite remote sensing of habitat suitability for ungulates and ostrich in the Kalahari of Botswana. Journal of Arid Environments 35, 563-574. doi:10.1006/jare.1996.0174

Wilson, B. A., Brocklehurst, P. S., Clark, M. J., and Dickinson, K. J. M. (1990). Vegetation survey of the Northern Territory, Australia. Explanatory notes to accompany 1:1000000 map sheets. Technical Report No. 49, Conservation Commission of the Northern Territory. (Northern Territory Government Printing Office: Darwin.)

Wintle, B. A., Elith, J., and Potts, J. M. (2005). Fauna habitat modelling and mapping: a review and case study in the Lower Hunter Central Coast region of NSW. Austral Ecology 30, 719-738. doi:10.1111/j.14429993.2005.01514.x
Wood, S. N. (2006). 'Generalized Additive Models: an Introduction with R.' (Chapman \& Hall: London.)

Wood, S. N. (2009). mgcv: GAMs with GCV/AIC/REML smoothness estimation and GAMMs by PQL. Version 1.5-5. Available at: http://cran. ms.unimelb.edu.au/web/packages/mgcv/index.html (accessed 19 June 2009.)

Zeng, B., and McGregor, M. (2008). Review of commercial options for management of feral camels. In: 'Managing the Impacts of Feral Camels in Australia: A New Way of Doing Business'. DKCRC Report 47. (Eds G. P. Edwards, B. Zeng, W. K. Saalfeld, P. Vaarzon-Morel and M. McGregor.) (Desert Knowledge Cooperative Research Centre: Alice Springs.)

Manuscript received 18 August 2009; accepted 17 December 2009 